\title{
A Detection Method of Earthquake Precursory Anomalies Using the Four-Component Borehole Strainmeter
}

\author{
Xiangyang Kong1, Kaizhi Su², Fujinawa Yukio ${ }^{3 *}$, Noda Yoichi ${ }^{4}$ \\ ${ }^{1}$ Earthquake Administration of Shandong Province, Jinan, China \\ ${ }^{2}$ Institute of Crustal Dynamics, China Earthquake Administration (CEA), Beijing, China \\ ${ }^{3}$ Organization for Development of Resilient Communities, Tokyo, Japan \\ ${ }^{4}$ Tierra-Tecnica Co. Ltd., Tokyo, Japan \\ Email: kxykxy2019@qq.com, kaizhisu@qq.com, ‘hjfujinawa@cl.cila s.net, \\ *fujinawa@mieruka.co.jp, dog_nodav@yahoo.co.jp
}

How to cite this paper: Kong, X.Y., Su, K.Z., Yukio, F. and Yoichi, N. (2018) A Detection Method of Earthquake Precursory Anomalies Using the Four-Component Borehole Strainmeter. Open Journal of Earthquake Research, 7, 124-140.

https://doi.org/10.4236/ojer.2018.72008

Received: January 1, 2018

Accepted: May 28, 2018

Published: May 31, 2018

Copyright (c) 2018 by authors and Scientific Research Publishing Inc. This work is licensed under the Creative Commons Attribution International License (CC BY 4.0).

http://creativecommons.org/licenses/by/4.0/

\begin{abstract}
Strainmeters have been used to detect earthquake precursory anomalies in many countries. An innovated four-component strainmeter with four sensing units set at 45 degrees intervals, named SKZ strainmeter, was developed and used in China. The design, with a few unique features, allows high-sensitivity monitoring of the regime of the crustal strain field, as well as the self-consistencies of the instrument. One of the most difficult problems in the earthquake precursory investigation is to efficiently detect anomalies from large amount of data. Pattern recognition of waveforms is widely used, but it is time-consuming and relies more or less investigator's experience and decision. In this study, the consistency factors of the paired components were firstly shown to be utilized to detect anomalies possibly related with imminent earthquakes. Here, rather than using the consistency factors, the correlation coefficients of the two orthogonal strain data were used to detect. SKZ strainmeters have been installed at more than ten sites in China, exhibited high efficiency and reliability in precursory monitoring since. Anomalous variations from a few stations during two recent earthquakes in south China were analyzed. During normal stages, diurnal earth tides could be clearly observed with very little urban noises. Though the consistency factors may have near constant bias, their correlation coefficients remain near 1.0, greater than 0.99 . During the imminent preparatory stage of earthquake occurrence, non-planar strain may appear and the correlation coefficients drop noticeably. The analysis showed that the correlation coefficient between the two orthogonal components is a useful parameter in post-processing of the strain data to detect precursory anomalies. The resultant resolving power is shown to be some one-order larger compared with previous methods.
\end{abstract}




\section{Keywords}

Borehole Strainmeter, Earthquake Observation Technology, Pre-Seismic Anomalies, Data Filtering

\section{Introduction}

Crustal strain monitoring using borehole strain meter has been widely conducted in China, Japan, USA, and Russia to detect anomalous precursory variations. Several types of sensors were used including original Sacks-Evertson model (Sacks et al., 1971 [1]), borehole extension sensor by Gladwin (1984 [2]), three-component volumetric strainmeter by Sakata (1981 [3], 2004 [4]), and multi-component system by Ishii and Yamauchi (2007 [5]), Ishii and Asai (2015 [6]).

The crustal deformation measurement related to earthquakes, volcanic eruption and plate movement has been conducted by using those kinds of strainmeters, borehole ground tilt meters, volumetric strainmeters (Agnew, 1986 [7]), and continuous Global Positioning System (GPS) (e.g., Rikitake, 1976 [8]; Su, 1977 [9]; Okada, 1985 [10]; Agnew, 1986 [7]; Qiu et al., 2011 [11]). For example, slow slip events (Obara, 2010 [12]) were identified by simultaneous observations of strain by Gladwin borehole strainmeters, GPS, and seismic tremors (Dragert and Wang, 2011 [13]; Hawthorne and Rubin 2013 [14]).

As for the earthquake prediction, the evaluation of candidate precursory anomalies relies on large amount of monitoring data from dozens or hundreds of sites in any countries as China, Japan, and USA along. Anomalies have been detected by discriminating patterns of waveforms by experienced reviewer, or trajectory of particle motions compared with those during normal stage (e.g., Okada et al., 2000 [15]; Ouyang et al., 2009 [16]; Ma and Wu, 2012 [17]). Automatic effective post-processing methods are greatly needed to identify candidate precursory phenomena using huge amount of data.

In this study, we used the redundant set of data of a specially designed four-component strainmeter to identify anomalies of the strain regime. The consistency parameters (Su, 1977 [9]) have been used to evaluate self-checking of the instrument for the network of the strainmeters (Roeloffs, 2010 [18]; Chen et al., 2015 [19]; Ishii and Asai, 2017 [20]). The parameter enables users to detect spurious variations at least due to the instrumental malfunctions. The correlation coefficients, along with the consistency relation, were used to identify anomalous variation originated from the non-planar strain field, which reflects the state of the crust in the preparatory process of earthquake.

\section{Methodology}

\subsection{SKZ Strainmeter}

A specially designed four-component strainmeter, named SKZ strainmeter, was 
invented in China in the 1970s ( $\mathrm{Su}, 1977$ [9]) and continuously improved since (Chi et al. 2009 [21]; Qiu et al. 2013 [22]). It has four gauges set at 45 degrees intervals to measure extension and contraction of the cylindrical housing in four different azimuths (Figure 1).

Three parameters to define the dynamical regime of crust under the condition of plain strain (i.e. the maximum principal stress, the minimum principal stress, and the direction of maximum principal stress) can be derived using any three of the four measured strains. The fourth set of measurement can be utilized for redundancy check. The consistency parameters have been used to evaluate quality of the data and the self-checking of the instrument for the strainmeter network (e.g., Chen et al., 2015 [19]). There is a consistency relation to characterize the regime of the crustal stress from the point of the horizontal strain.

The SKZ strainmeter is a long cylinder for radial displacement detection. Four sensing elements are installed in the middle of the cylinder to detect North-South (NS), North-West (NW), West-East (WE), and South-West (SW) alignments and deformations (Figure 1). Difference between the angles of two adjacent sensors is 45 degrees, which are equally distributed in accordance with the asterisk configuration.

Displacement transferring mechanism of the SKZ strainmeter was designed to increase sensitivity and accuracy. Eight narrow ribs were set precisely in the position where sensing elements were installed (see Figure 2). Metal cylinder casing with the ribs is cut from a single-piece, thick-walled metal tube using computer-controlled machines. The two polar plates of the capacitive sensors are arranged on the symmetrical fine ribs to constitute a simple non-contact measurement sensor. The SKZ units are shown in Figure 3, and specifications are summarized in Table 1.

\subsection{Installations}

The cylinder probe is installed into a borehole formation. The probe and formation

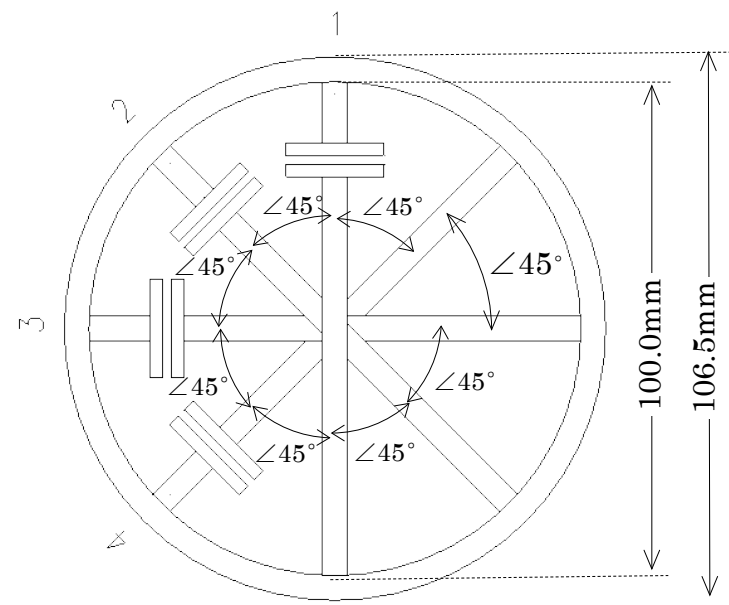

Figure 1. Schematic configuration. 


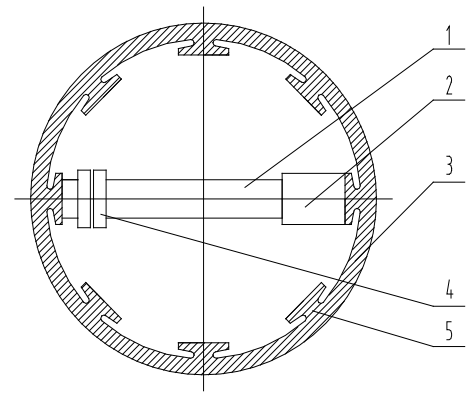

(a)

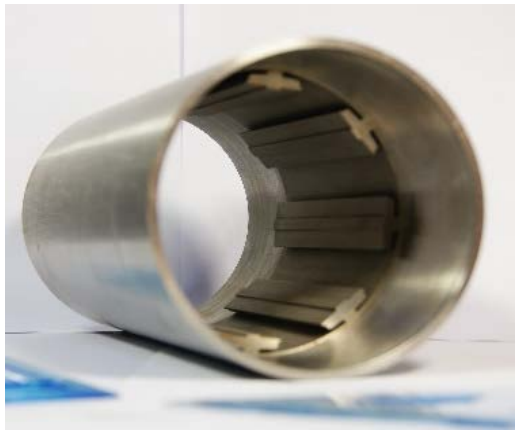

(b)

Figure 2. Structure of SKZ strainmeter. (a) Internal structure of the instrument: 1-quarts baseline rod; 2-zero component; 3-metal cylinder casing; 4-capacitance plate; 5-narrow ribs; (b) Photograph of the cylinder.

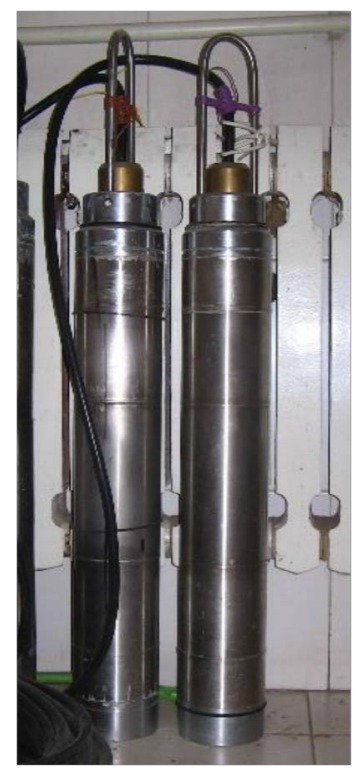

Figure 3. External appearance of two sets of the SKZ atrainmeters.

are bonded using the coupling medium. The first SKZ strainmeter was installed in Yiliang Station, Yunnan Province in March 2007, and followed by nine sites in several provinces in China, as shown in Table 2 and Figure 4. The depths of the installation range from 50 meters at the Yiliang Station to 135 meters at Dagan Station. The typical installation depth is several tens meters to reduce meteorological noises as far as possible (Qiu et al., 2013 [22]).

Figure 5 illustrates 24 -hour data record sampled at every half a minute rate at Datong Station in the Shanxi Province. The noise level at the site is around $5 \times$ $10^{-9}$, much less than the solid earth tide influences.

\subsection{Data Processing}

When a strainmeter is installed close to the surface, the measured strain field can be generally considered to be horizontal, because vertical normal stress is 
Table 1. SKZ strainmeter specifications.

\begin{tabular}{cc}
\hline Parts & Dimension \\
\hline Probe diameter & $106 \mathrm{~mm}$ \\
Probe length & $900 \mathrm{~mm}$ \\
Probe weight & $27 \mathrm{~kg}$ \\
Specific gravity of probe & 3.5 \\
Number of component & 4 \\
Sensitivity & $4 \times 10^{-9} / \mathrm{mV}$ \\
Noise & $0.03 \mathrm{mV}$ \\
Linearity & Approximately equal to $1 \%$ \\
Bandwidth & $100 \mathrm{~Hz}$ \\
Self stability & $10^{-7} / \mathrm{year}$ \\
Calibration range & less than $1 \%$ \\
(Non-zero) adjustment range & $7 \times 10^{-8}$ \\
Mechanical zero amplitude & $\pm 10^{-5}$ \\
Underground instrument power & $1 \times 10^{-3}$ \\
\end{tabular}

Table 2. SKZ strainmeter installations.

\begin{tabular}{cccccc}
\hline $\begin{array}{c}\text { Serial } \\
\text { number }\end{array}$ & $\begin{array}{c}\text { Site } \\
\text { (city, province) }\end{array}$ & Date & Lithology & $\begin{array}{c}\text { Depth } \\
(\mathrm{m})\end{array}$ & $\begin{array}{c}\text { Probe diameter } \\
(\mathrm{mm})\end{array}$ \\
\hline 1 & Lianyungang, Jiangsu & December, 2006 & Granite & 65 & 106 \\
2 & Yiliang, Yunnan & March, 2007 & Sandstone & 55 & 106 \\
3 & Dushanzi, Xinjiang & December, 2008 & Limestone & 60 & 106 \\
4 & Yudong, Yunnan & May, 2010 & Sandstone & 56 & 106 \\
5 & Qingdao, Shandong & December, 2010 & Granite & 68 & 106 \\
6 & Dagan, Yunnan & November, 2011 & Limestone & 135 & 88 \\
7 & Weixin, Yunnan & November, 2011 & Limestone & 70 & 106 \\
8 & Datong, Shanxi & December, 2011 & Gneiss & 66 & 106 \\
9 & Ludian, Yunnan & February, 2014 & Limestone & 86 & 106 \\
10 & Yanjin, Yunnan & March, 2014 & Basalt & 80 & 106 \\
\hline
\end{tabular}

negligible. The sensor is expected to provide independent observations on strain variations in line with other geodetic observations such as GPS and InSAR.

Under this situation, the displacements $\left(U_{1} \sim U_{4}\right)$ of the four sensors are described by principal strains $\varepsilon_{1}, \mathcal{E}_{2}$ as follows (Su, 1977 [9]).

$$
\begin{gathered}
U_{1}=A\left(\varepsilon_{1}+\varepsilon_{2}\right)+B\left(\varepsilon_{1}-\varepsilon_{2}\right) \cos 2(\Psi-\varphi) \\
U_{2}=A\left(\varepsilon_{1}+\varepsilon_{2}\right)-B\left(\varepsilon_{1}-\varepsilon_{2}\right) \sin 2(\Psi-\varphi) \\
U_{3}=A\left(\varepsilon_{1}+\varepsilon_{2}\right)-B\left(\varepsilon_{1}-\varepsilon_{2}\right) \cos 2(\Psi-\varphi) \\
U_{4}=A\left(\varepsilon_{1}+\varepsilon_{2}\right)+B\left(\varepsilon_{1}-\varepsilon_{2}\right) \sin 2(\Psi-\varphi)
\end{gathered}
$$




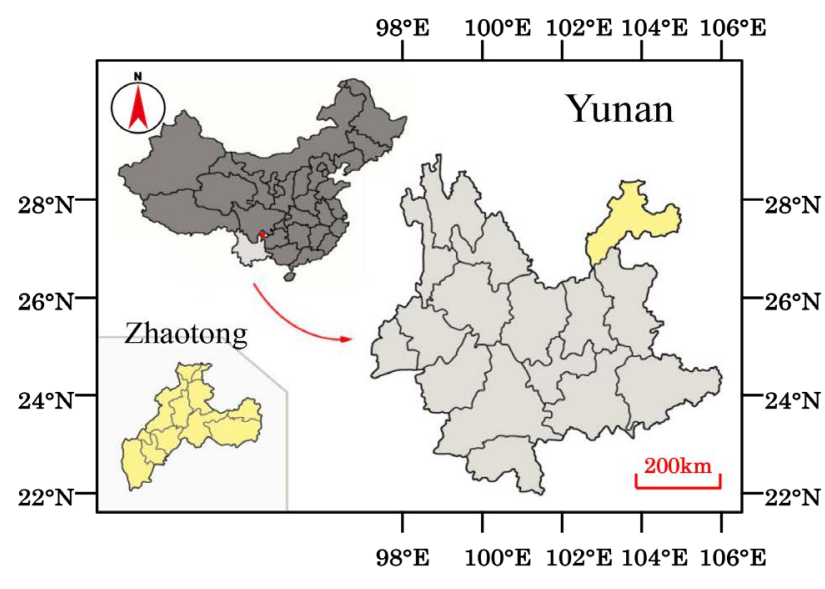

(a)

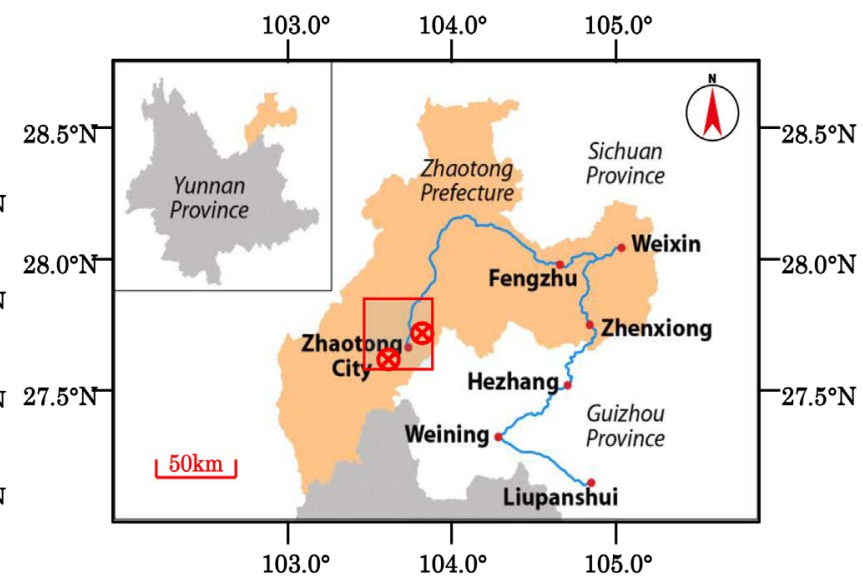

(b)

Figure 4. Locations of Yiliang earthquake and Ludian earthquake.

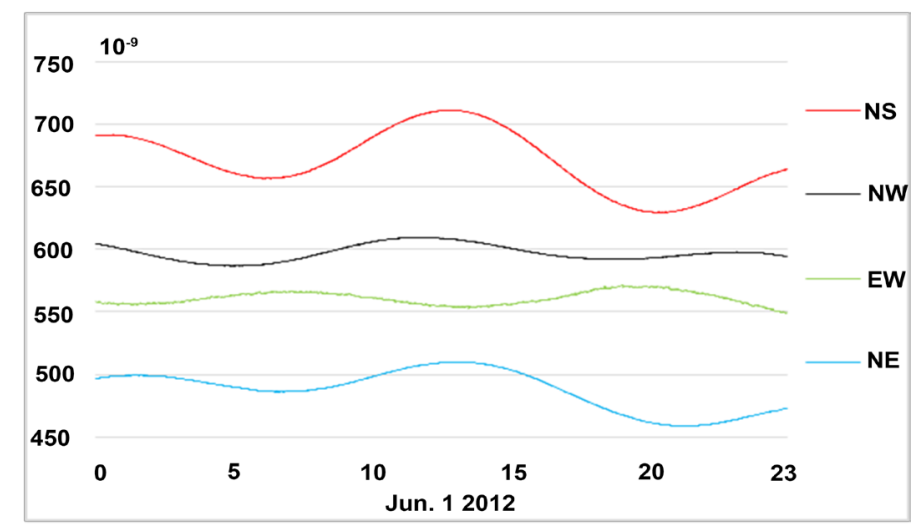

Figure 5. Typical readings during normal stage at Datong station, Shanxi Province.

where $\Psi$ is azimuth of the principal stress, $\varphi$ is the direction of the first sensing element, $A$ and $B$ are constants depending on parameters of the borehole (the radial displacement of the cylinder inner) and the crustal strain. $A$ is the sensitivity coefficient to the areal strain, $B$ is the sensitivity coefficient to the shear strain. These two coefficients are related with the mechanical parameters of cement and rock, and also related the cement layer depth, the inner and outer diameter of the cylinder. Normally $A$ was significantly less than 1 , and $B$ was significantly greater than 1 .

The following equations can be derived ( $\mathrm{Su}, 1977$ [9]),

$$
\begin{gathered}
U_{o}=\left(U_{1}+U_{3}\right) \\
U_{e}=\left(U_{2}+U_{4}\right) \\
U_{o}=U_{e}=U c
\end{gathered}
$$

Because the sum of odd-numbered displacements $\left(U_{o}\right)$ equals to that of the even-numbered $\left(U_{e}\right)$, Equation $5 c$ actually is a self-consistent equation ( $\mathrm{Su}, 1977$ [9]), which provides a check relation among the four parameters.

$U c$ is related to surface strain $\left(\varepsilon_{1}+\varepsilon_{2}\right)$ as shown in Equation (6). 


$$
U c=2 R\left(\varepsilon_{1}+\varepsilon_{2}\right)
$$

It is a parameter of the plane strain independent of directions $\Psi$ and $\varphi$. The difference between the measured values for mutually vertical sensors $U a$ and $U b$,

$$
\begin{aligned}
& U a=U_{1}-U_{3}=4 R\left(\varepsilon_{1}+\varepsilon_{2}\right) \cos 2(\Psi-\varphi) \\
& U b=U_{2}-U_{4}=-4 R\left(\varepsilon_{1}-\varepsilon_{2}\right) \sin 2(\Psi-\varphi)
\end{aligned}
$$

are related only to the differential stresses, $\left(\varepsilon_{1}-\varepsilon_{2}\right) . \Psi$, the direction of the principal stress, can be determined by the ratio of $U b$ to $U a$ (Su, 1977 [9]).

$$
U b / U a=-\tan 2(\Psi-\varphi)
$$

Measurements of the four components can reflect the plane strain regime, if the consistency relation (Equation (5)) is generally fulfilled. Otherwise, the inconsistency may be a result of system malfunction and/or anomalous variations regime of the crust which induces non-planer strain. The redundant data can be used for self-checking providing better performance compared with other types of borehole strainmeters (e.g., Gladwin, 1984 [2]; Sakata and Sato, 1986 [23]; Hart et al., 1996 [24]; Ishii, 2001 [25]).

The consistency relation can be used as an indicator of data quality (Chen et al., 2015 [19]). Moreover, the relation can also be used to detect anomalous variations as a result of the breakdown of the normal state of plain strain around the region of earthquake preparation.

\subsection{Normal Stage}

Figure 6 is an example of monthly data sampled at one per minute at the Daguan Station in the Yunnan Province between May 1 and May 31, 2012 (Table 2 and Figure 4). Two dominant variations in each component are steady with diurnal and semi-diurnal changes induced by solid earth tides. The trends of NS and NW components are almost linear, but EW and NE components are superposed by small random disturbances lasting for several days. The trends of the components are different from these reported by Sakata and Sato (1986) [23]. However our present object is to focus on shorter-period variations from the viewpoint of short-term earthquake predictions.

Figure 7 shows the calculated surface strains, $U_{o}(5 \mathrm{a})$ and $U_{e}(5 \mathrm{~b})$ at Datong Station in Shanxi Province from June 1, 2012 to July 31, 2012. They are nearly equal, proving the self -consistency relation except the small trends. The difference between $U_{o}$ and $U_{e}$ is about $2.0 \times 10^{-7}$ except for the shorter frequency components. It proved that the instrument is very steady and the consistency has been conserved for a very long period of a month or longer.

The rate of the satisfaction of self-consistency relation is defined by a ratio between the difference and the mean of the $U_{o}$ and $U_{e}$ by Qiu et al. (2013) [22], as shown below.

$$
C 95=1-\frac{\sum_{N 95}\left|\left(U_{o}-U_{e}\right)\right|}{\sum_{N 95}\left(U_{o}+U_{e}\right)}
$$




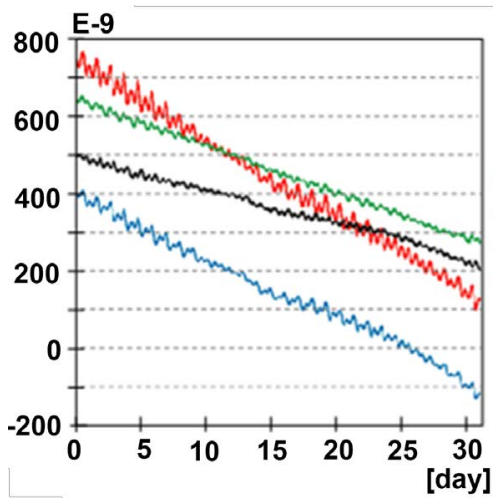

(a)

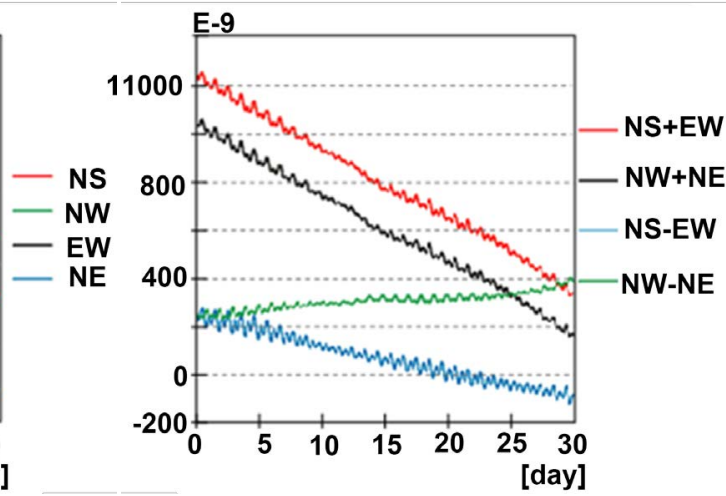

(b)

Figure 6. Typical readings during normal stage at Datong Station, Shanxi Province. (a) Original data; (b) Surface strain and shear strain.

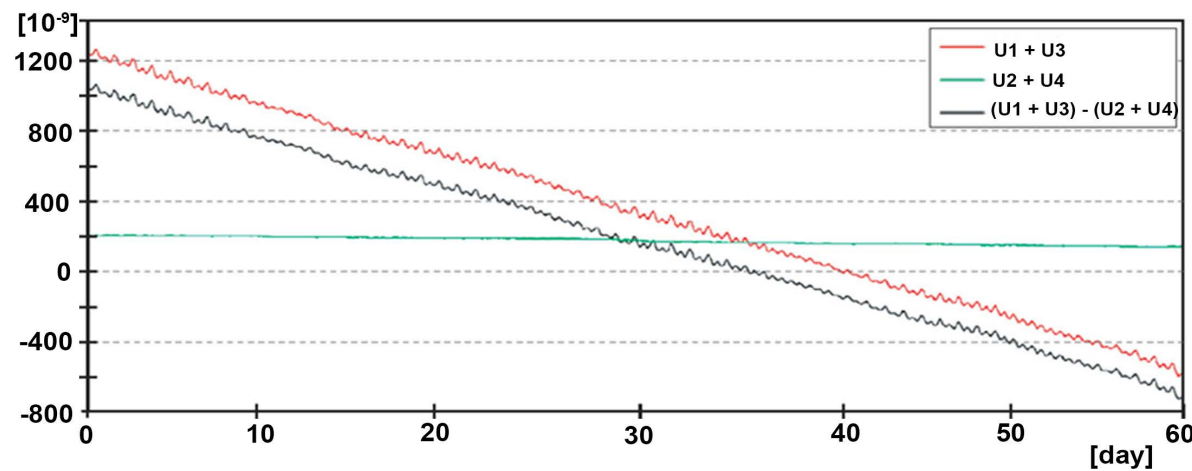

Figure 7. Surface strains $U c o\left(\mathrm{U}_{1}+\mathrm{U}_{3}\right)$ and $U c e\left(\mathrm{U}_{2}+\mathrm{U}_{4}\right)$ at Datong Station, Shanxi Province (June 1, 2012 to July 31, 2012).

After eliminating the $5 \%$ outliers, the remaining correlation coefficients between $U_{o}$ and $U_{e}$, instead of the self-consistency relation itself, was used to evaluate performances at particular sites.

The alternative parameter to quantize qualities of strain data that we use is the Pearson's correlation coefficient $C P$, which utilizes 25 data sampled at a once-per hour rate shifting by an hour. The selection is based on the fact that dominant components are the diurnal and semi-diurnal lunar tidal components $S_{1}(25.82$ hours) and $\mathrm{M}_{2}$ (12.42 hours) solid tides. The correlation coefficient $C p$ is defined from the following:

$$
C p=\frac{\operatorname{Cov}\left(U_{o}, U_{e}\right)}{\sigma_{U_{o}} \sigma_{U_{e}}}
$$

where Covis the covariance, and $\sigma$ is the standard deviation.

\section{Results}

\subsection{Yiliang Earthquake}

Yiliang earthquake (M 5.7) occurred on September 7, 2012, in the Luozehe Town (104.0E, 27.5N), $15 \mathrm{~km}$ south of Yiliang County center (Figure 8). 


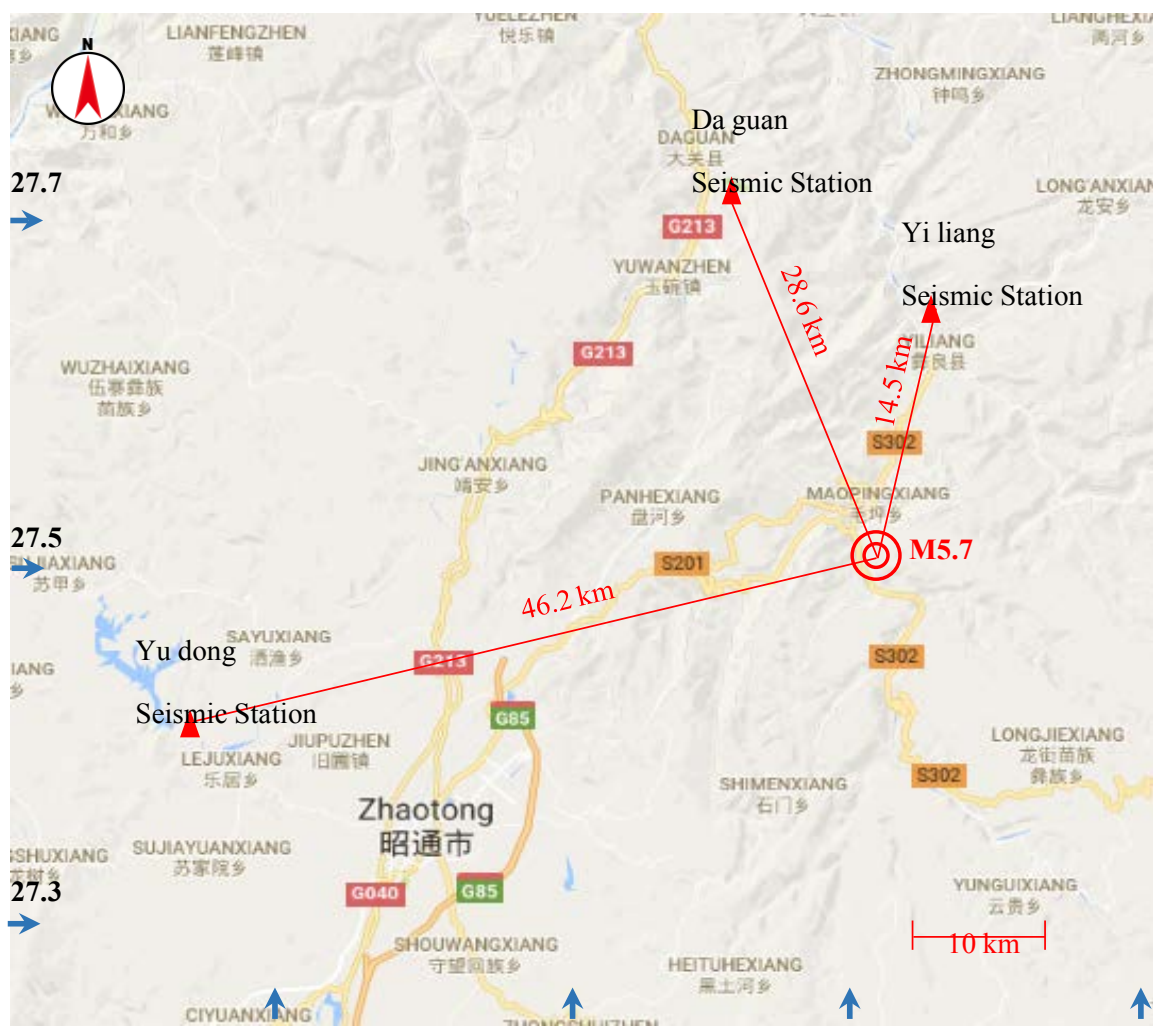

Figure 8. A geographic ralation concerning the Yilian Earthquake (M5.7) which occurred in the midst of the present strain observation network. The sesimic stations are indicated by red triangle.

\subsubsection{Yiliang Station ( $14.5 \mathrm{~km}$ from Epicenter)}

Yiliang Station is located north of Yiliang County (104.06E, 27.63N). The geology at the site where SKZ strainmeter was installed has an intact pink sandstone. Seven days before Yiliang earthquake, obvious strain anomalous variations were recorded in all measured directions at the Yiliang Station (Figure 9(a)). Atmospheric pressure, groundwater level, solid tides and other noises were deliberately investigated to detect meaningful changes from the observational data $(\mathrm{Su}$, 2003 [26]). In general, the precipitation induces changes of surface loading, confined water pressure changes, and the water level changes, which caused crustal stress variations.

Additional observations were also conducted for the water level and temperature at the site including the water level of the nearby to check effect of the precipitation, strong winds, and drought. In this report, no detailed description was given to these effects because of very little precipitation in the observation period with the result of negligible effects in the higher frequency band of our present interest (Su, 2003 [26]).

Several kinds of anomalous variations were observed at the Yeliang station before the earthquake (Figure 9(a)). Small abrupt changes of strains were clearly recorded by NS, NW, NE, and NE components on August 4, September 1, September 7 (co-seismic) and September 10 respectively. These anomalous variations are clearly seen in the plotting of the correlation coefficients proving much 


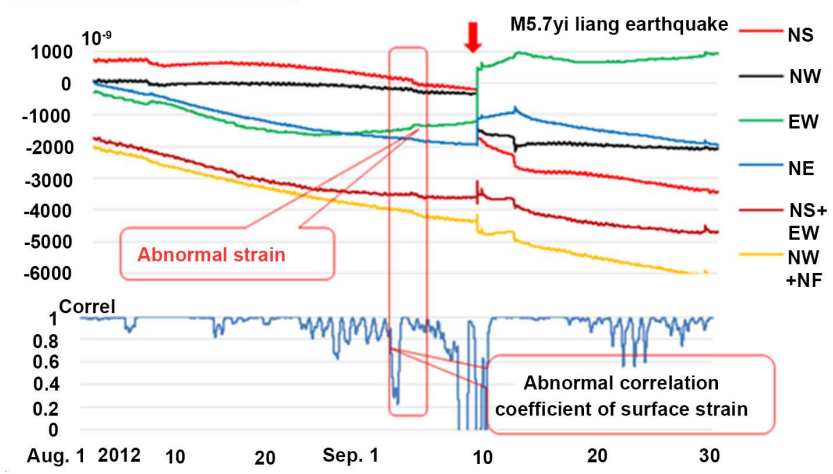

(a)

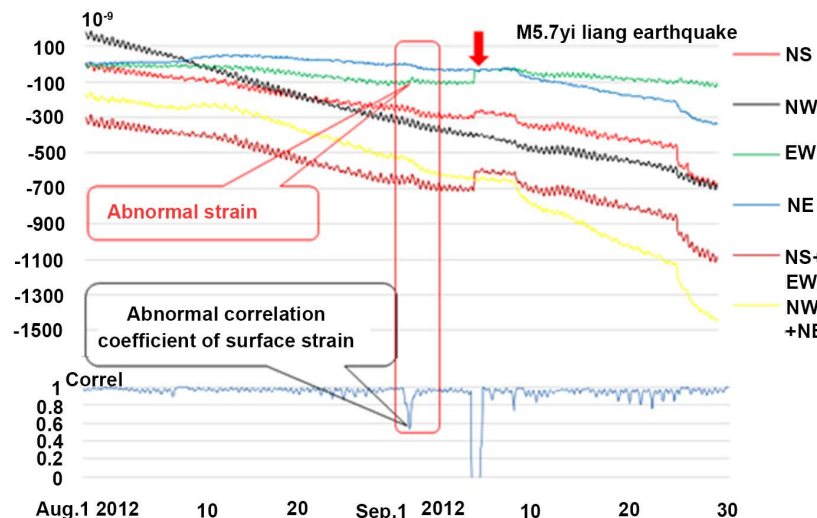

(b)

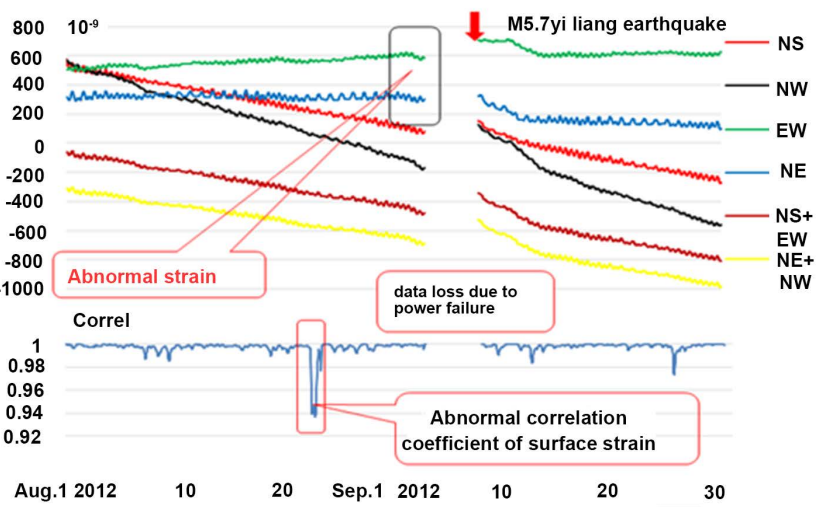

(c)

Figure 9. Anomalous strain variations before Yiliang earthquake. (a) Yiliang Station; (b) Yudon Station; (c) Daguan Station.

larger resolving power, some one order larger than using waveform characteristics. The correlation coefficients were close to 1.0 during normal stages, but the correlation rapidly decreased possibly due to slight anomalies of the strain occurring for nearly a whole day on August 7, a month before the earthquake. The correlation coefficient dropped to 0.2 , indicating that larger non-planar strain changes were superposed to the normal planar strain undulations induced by the earth tides. The very small anomalies appeared in the waveform is amlified about one order in the case that the correlation coefficient is selected as an indicator.

\subsubsection{Yudon Station ( $45 \mathrm{~km}$ from Epicenter)}

Approximately seven days before the Yiliang earthquake, a small sharp increase in NE and EW components were recorded and correlation coefficients dropped to 0.6 (Figure 9(b)). The co-seismic changes were significant in the NS and EW components, and minor in the NW component. Except the two periods during the imminent stage and co-seismic time, the correlation coefficient between $U_{o}$ and $U_{e}$ were near 1.0, indicating the plain strain regime was preserved. These phenomena were more obvious on September 25, suggesting existence of a large-scale non-planar strain. The anomalous phenomena at the Yudon station is much small compared with those at the Yelian station possibly because of 
large difference of epicentral distance. However the smaller anomaly can be detected by means of the correlation coefficient same as at the Yeliang station.

\subsubsection{Daguan Station (29 km from Epicenter)}

The Daguan Station, 29 kilometers away from epicenter, did not show significant anomalous variations at around time when clear anomaries were detected at Yudon and Yeliang sites. The correlation coefficients were stable in general, with exception of a small drop to approximate 0.97 ten days before the earthquake. The Daguan site shows very different changes compared with other two sites. There are no large decrease of the correlation coefficients not larger than 0.04. However there appeared clear minimum appeared several days before compared with those of other two sites. These phenomena suggest that the earthquake preparatory process is not uniformly distributed both in space and in time. The absence of significant changes could be explained by the spatial location of the Daguan station, which is situated perpendicular to the geographic direction of sites Yudong and Yiliang in reference to the epicenter.

\subsection{Ludian Earthquake}

The Ludian M6.5 earthquake occurred on August 3, 2014 and the epicenter was located in Ludian County in Yunnan Province (Figure 10). Figures 11(a)-(d) show the strain changes and the correlation coefficient at Ludian, Yudon, Yiliang, and Daguan stations during Ludian earthquake, respectively.

\subsubsection{Ludian Station ( $31 \mathrm{~km}$ from Epicenter)}

The Ludian station is located in Ludian City (103.56E, 27.20N). The rocks near the strainmeter are limestones and intact bedrocks. Urban noises at the Ludian station is very low, except a slight shift due to the consolidation of the portland cement used in the installation (Su et al., 2003 [26]). The correlation coefficient is generally high except a small decrease to 0.85 , two weeks before the earthquake, followed by a more significant drop three days before the earthquake.

\subsubsection{Yudon Station ( $39 \mathrm{~km}$ from Epicenter)}

There appear almost none anomalies in the waveform of the strain data (NS, $\mathrm{NW}, \mathrm{EW}, \mathrm{NE}$ ) and two consistent factors (NS + EW, NW + NE). A slight decrease of the correlation coefficients (as low as 0.90) at Yudong station was seen just before the earthquake though with considerable ambiguity. There appeared no other noticeable anomalous variations change at the Yudon station before the Lucian earthquake. The correlation coefficents evolves characteristically just before the earthquake suggesting that there are some anormal regime of crustal strain field. Other anomalies occurred from some 10, August to 25, August cannot explained at this time.

\subsubsection{Yiliang Station ( $91 \mathrm{~km}$ from Epicenter)}

Correlation coefficient variations at Yiliang Station did not decreased significantly 


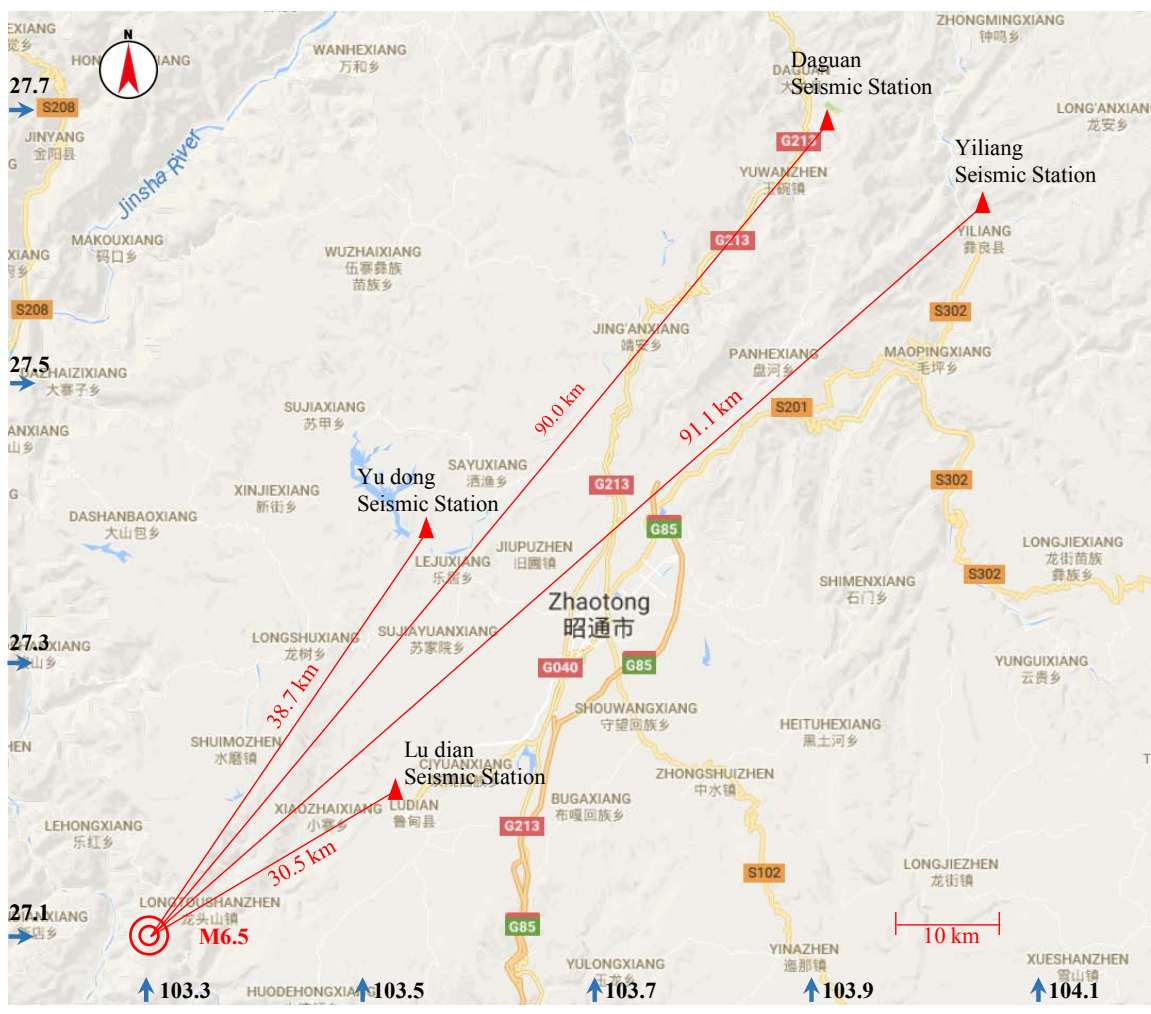

Figure 10. A geographic ralation concerning the Ludian Earthquake (M5.5) which occurred southwest of the present strain observation network. The sesimic stations are indicated by red triangle. The nearest site is the Ludian site.

compared with these at the Ludian station. However, a steady decrease of correlation coefficients (as low as 0.70 ) was recorded just before the earthquake. The correlation coefficents evolves characteristically just before the earthquake suggesting that there are some anormal regime of crustal strain field. Other anomalies occurred from some 10, August to 25, August cannot explain at this time.

\subsubsection{Daguan Station ( $90 \mathrm{~km}$ from Epicenter)}

Anomalous strain variations at the Daguan station were not significant, nor the decrease of the correlation coefficient. Strain measurements slightly changed three days before the Ludian earthquake without any systematical evolution except sporadic decrease of the correlation coefficient.

\subsection{Summary of Precursory Anomalies}

It is shown that the anomalous strain decreased as distances from earthquake epicenter increased. The changes of the correlation coefficients (Equation (11)) between the two components of consistency relation $U_{o}$ and $U_{e}$ are proved to characterize the preparatory stage of the earthquake (Table 3 ). Correlation coefficients during normal stages were typically between 0.8 and 0.98 , substantially decreased during the imminent stage of the earthquake, and return to 0.98 or higher after the earthquake. 


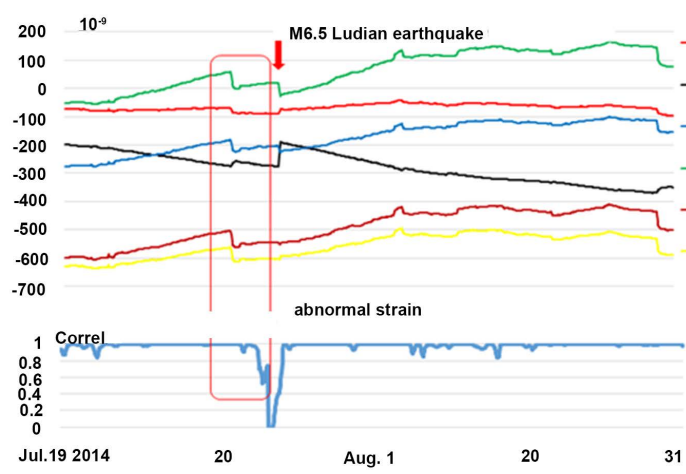

(a)

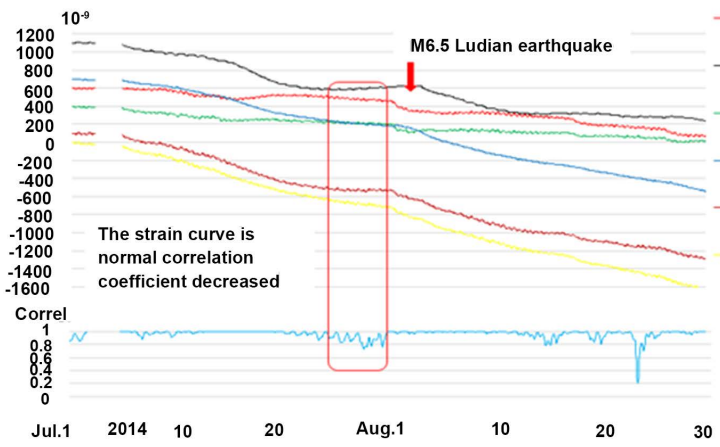

(c)

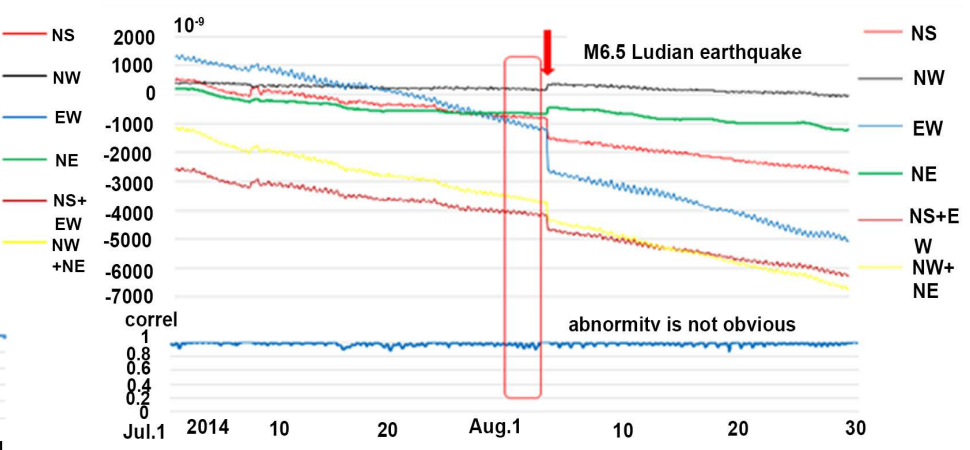

(b)

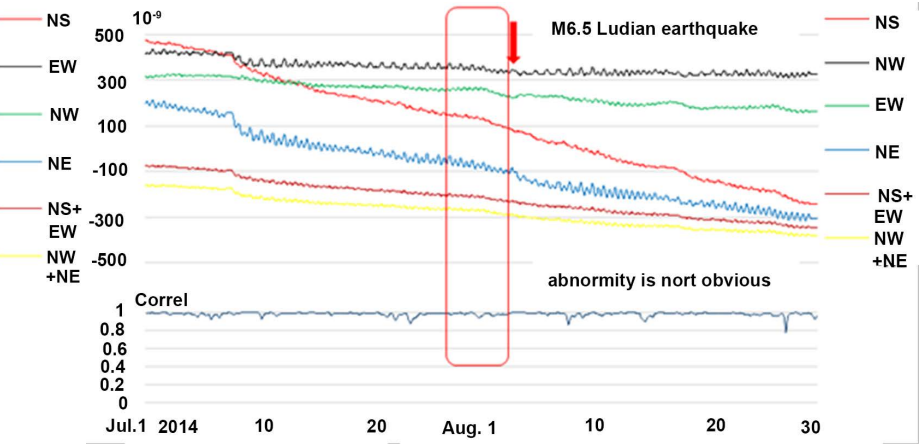

(d)

Figure 11. Anomalous variations at Ludian Station before Ludian Earthquake (July 19 to September 29, 2014). (a) Ludian; (b) Yudon; (c) Yiliang; (d) Daguan.

Table 3. Correlation coefficients of surface strain during Ludian earthquake. During normal stages it is typically between 0.8 and 0.98 , slightly decreased during the imminent stage, and return to near 1.0 after the earthquake.

\begin{tabular}{ccccc}
\hline Date & July/22-July/31 & July/31-August/3 & August/3-/11 & August/1-August/30 \\
\hline $\begin{array}{l}\text { Correlation } \\
\text { coefficients }\end{array}$ & 0.98 & 0.83 & 1 & 0.98 \\
Anomality & Normal & Precursor & Post-quake & Post-quake stability \\
\hline
\end{tabular}

\section{Discussions}

The correlation coefficient has been used as an index parameter to characterize the preparatory stage instead of the consistency relation itself. The correlation coefficient was calculated using 25 -hour data because the dominant components were $\mathrm{M}_{2}$ and diurnal periods of $\mathrm{O}_{1}$. The correlation coefficient between $U_{o}$ and $U_{e}$ as thought to reflect the rate of the deviation of the strain from the normal planar regime of the crust. Because of the dominance of earth tides, our approach to use the correlation is consistent with previous approaches on borehole strainmeter calibration using earth tides (e.g., Hart et al., 1996 [24]; Chen et al., 2015 [19]).

The decreased correlation coefficients prior to major earthquakes could be due to occurrence of considerable amount of non-planer strain associated with precursory deformation of the crust. It is known that the deviation of the ob- 
served earth tides at the normal state are also related to instrument responses, surface loading, and local crustal structures. The instrumental responses included the coupling mechanism between the instrument and the crust (e.g., Beaumont and Berger, 1975 [27]; Kohl and Levine, 1995 [28]; Chen et al, 2015 [19]). The possibility of instrumental malfunction and noise could be decreased by referring the solid earth tide by the solid tide evolution during normal stage, but cares should be taken to consider the possibility of malfunctions and noise with anomalies of strains. Multiple measurements using four-component borehole strainmeters, electromagnetic wave meters (Fujinawa et al., 2013 [29], Fujinawa and Noda, 2016 [30]), and water level sensors (e.g., Lai et al., 2010 [31]) can provide further evidences to infer if the anomalies were related to the preparatory process as well as to explore the mechanism of abnormal stain changes.

In associations with the pre-slip occurrence or local fluid movement around the preparatory region near the epicenter before the earthquake, a small change of crustal strain would have been induced near epicenter. The physical mechanism may be the dilatancy effects (Berger, 1974), occurrence of microcracks (Fujinawa et al., 2013 [29], Fujinawa and Noda 2016 [30]), or movement of the confined fluid (Lai et al., 2010 [31]).

Replacing the internal capacitive displacement sensor unit to a piezoelectric ceramic piece could simplify the mechanical structure and electronic circuit by force-electric conversion of the piezoelectric element. We can expect the cost to decrease by about one third and the sensitivity to increase up to an order of $10^{-11}$.

\section{Conclusions}

The special four-component strainmeter SKZ-1 can provide a simple indicator (consistency factor) to reflect the regime of the crust, which is dominated by plain strain under normal conditions. This can be further utilized to identify candidates of anomalous variation with smaller ambiguities. Specially designed SKZ strainmeter has been installed at more than 10 sites in several provinces in China, with more than 10 years of observations. Reliable performances with high stability and high resolution for detecting local and regional anomalous variations were exhibited. During the normal stage, the variations were consisted of steady diurnal variations due to earth tides. Urban noises around are low and the consistency factor calculated using 25-hours average is fairly close to 1.0.

A new detecting method of anomalous variations was introduced by studying the correlation coefficient of two independent plain strain components in this paper. Observations during two major earthquakes in southern China (Yiliang earthquake and Ludian earthquake) were discussed. During the imminent stage, obvious strain anomalies were recorded simultaneously by the four components at sites close to the epicenters. The correlation coefficients between orthogonal components $U_{o}$ and $U_{e}$ dropped below 0.2 , compared to near 1.0 during normal stage. The correlation coefficient can be used to objectively detect anomalies during the successive stages of an earthquake's occurrence from normal to re- 
laxation stages. Results indicated that the correlation coefficient provides useful means to identify preparatory stage from large amount of data with the help of SKZ strainmeter designs.

\section{Acknowledgements}

Great thanks are expressed to the Institute of Crustal Dynamics of CEA, Earthquake Administration of Shandong Province, Earthquake Administration of Yunnan Province, and especially to the Earthquake Administration of Zhaotong City for providing test sites.

\section{References}

[1] Sacks, S., Suyehiro, W., Evertson, D.W. and Yamagishi, Y. (1971) A CKS-Evertson Strainmeter, Its Installation in Japan and Some Preliminary Results Concerning Strain Steps. Papers in Meteorology and Geophysics, 22, 195-208.

[2] Gladwin, M.T. (1984) High Precision Multi-Component Borehole Deformation Monitoring. Review of Scientific Instruments, 55, 2011-2016.

https://doi.org/10.1063/1.1137704

[3] Sakata, S. (1981) On the Concepts of Some Newly-Invented Borehole Three-Component Strainmeters. Rep. Natl. Res. Cent. Disas. Prev., 25, 95-126. (In Japanese)

[4] Sakata, S. (2004) Basic Theory of Sakata-Type Three-Component Strainmeter. Journal of the Geodetic Society of Japan, 50, 213-226.

[5] Ishii, H. and Yamauchi, T. (2007) Development of Multi-Component Borehole System for Crustal Activity Observation, Obtained Results and Future Observation. Journal of Geodetic Society of Japan, 53, 99-111.

[6] Ishii, H. and Asai, Y. (2015) Development of a Borehole Stress Meter for Studying Earthquake Predictions and Rock Mechanics, and Stress Seismogromas of the 2011 Tohoku Earthquakes (M9.0). Planet and Space, 67, 26.

[7] Agnew, D.C. (1986) Strainmeters and Tiltmeters. Reviews of Geophysics, 24, 579-624. https://doi.org/10.1029/RG024i003p00579

[8] Rikitake, T. (1976) Earthquake Prediction. Elsevier Sci. Publ. Co., New York.

[9] Su, K.Z. (1977) Methods of Relative Measurement of Ground Stress. In: Selected Papers of the National Conference on Stress Measurement, Part 1, 42-61. (In Chinese)

[10] Okada, Y. (1985) Surface Deformation Due to Shear and Tensile Faults in a Half-Space. Bulletin of the Seismological Society of America, 75, 1135-1154.

[11] Qiu, Z.H., Zhang, B.H., Chi, S.L., Tang, L. and Song, M. (2011) Abnormal Strain Changes Observed at Guza before the Wenchuan Earthquake. Science in China Series D-Earth Sciences, 54, 157-314.

[12] Obara, K. (2010) Phenomenology of Deep Slow Earthquake Family in Southwest Japan: Spatiotemporal Characteristics and Segmentation. Journal of Geophysical Research: Solid Earth, 115, B00A25. https://doi.org/10.1029/2008JB006048

[13] Dragert, H. and Wang, K. (2011) Temporal Evolution of an Episodic Tremor and Slip Event along the Northern Cascadia Margin. Journal of Geophysical Research: Solid Earth, 116, B12406. https://doi.org/10.1029/2011JB008609

[14] Hawthorne, J.C. and Rubin, A.M. (2013) Short-Time Scale Correlation between 
Slow Slip and Tremor in Cascadia. Journal of Geophysical Research: Solid Earth, 118, 1316-1329. https://doi.org/10.1002/jgrb.50103

[15] Okada, Y., Yamamoto, E. and Ohkubo, T. (2000) Coswarm and Preswarm Crustal Deformation in the Eastern Izu Peninsula, Central Japan. Journal of Geophysical Research: Solid Earth, 105, 681-692. https://doi.org/10.1029/1999JB900335

[16] Ouyang, Z.X., Zhang, H.X., Fu, Z.Z., Gou, B. and Jiang, W.L. (2009) Abnormal Phenomena Recorded by Several Earthquake Precursor Observation Instruments before the $M_{s}$ 8.0 Wenchuan, Sichuan Earthquake. Acta Geologica Sinica, 83, 834-844. https://doi.org/10.1111/j.1755-6724.2009.00106.x

[17] Ma, T.F. and Wu, Z.L. (2012) Precursor-Like Anomalies Prior to the 2008 Wenchuan Earthquake: A Critical-but-Constructive Review. International Journal of Geophysics, 2012, Article ID: 583097. https://doi.org/10.1155/2012/583097

[18] Roeloffs, E. (2010) Tidal Calibration of Plate Boundary Observatory Borehole Strainmeters: Roles of Vertical and Shear Coupling. Journal of Geophysical Research: Solid Earth, 115, B06405. https://doi.org/10.1029/2009JB006407

[19] Chen, Z.H., Lü, P.J. and Tang, L. (2015) Quality Analysis of Crustal Tilt and Strain Observations in China's Earthquakes in 2014. Geodesy and Geodynamics, 6, 467-481. https://doi.org/10.1016/j.geog.2015.12.007

[20] Ishii, H. and Asai, Y. (2017) Elastic Invariants Observed by Borehole Stress and Strain Meters, and the Reliability of the Instruments. Zisin, 69, 49-58.

[21] Chi, S.-L., Chi, Y., Deng, T., Liao, C.-W., Tang, X.L. and Chi, L. (2009) The Necessity of Building National Strain-Observation Network from the Strain Abnormality before Wenchuan Earthquake. Recent Developments in World Seismology, 1, 1-13. (In Chinese)

[22] Qiu, Z.H, Tang, L., Zhang, B.H. and Guo, Y.P. (2013) In Situ Calibration of and Algorithm for Strain Monitoring Using Four-Gauge Borehole Strainmeters (FGBS). Journal of Geophysical Research: Solid Earth, 118, 1609-1618.

[23] Sakata, S. and Sato, H. (1986) Borehole-Type Tiltmeter and Three-Component Strainmeter for Earthquake Prediction. Journal of Physics of the Earth, 34, S129-S140.

[24] Hart, R., Gladwin, M.T., Gwyther, R.L., Agnew, D.C. and Wyatt, F.K. (1996) Tidal Calibration of Borehole Strain Meters: Removing the Effects of Small-Scale Heterogeneity. Journal of Geophysical Research: Solid Earth, 101, 25553-25571. https://doi.org/10.1029/96JB02273

[25] Ishii, H. (2001) Development of New Multi-Component Borehole Instrument. Report of Tono Research Institute of Earthquake Science, 6, 5-10. (In Japanese)

[26] Su, K.Z., Li, H.L. and Zhang, J. (2003) The New Progress of Borehole Strain Observation. Beijing Seismological Press, Beijing. (In Chinese)

[27] Beaumont, C. and Berger, J. (1975) An Analysis of Tidal Strain Observations from the United States of America, I, The Homogeneous Tide. Bulletin of the Seismological Society of America, 65, 1613-1629.

[28] Kohl, M.L. and Levine, J. (1995) Measurement and Interpretation of Tidal Tilts in a Small Array. Journal of Geophysical Research: Solid Earth, 100, 3929-3941. https://doi.org/10.1029/94JB02773

[29] Fujinawa, Y., Noda, Y., Takahashi, K., Kobayashi, M., Takamatsu, K. and Natsumeda J. (2013) Field Detection of Microcracks to Define the Nucleation Stage of Earthquake Occurrence. International Journal of Geophysics, 2013, Article ID: 651823. https://doi.org/10.1155/2013/651823 
[30] Fujinawa, Y. and Noda, Y. (2016) Characteristics of Seismoelectric Wave Fields Associated with Natural Microcracks. Pure and Applied Geophysics, 173, 255-268. https://doi.org/10.1007/s00024-015-1043-8

[31] Lai, W.C., Hsu, K.C., Shiehu, C.L., et al. (2010) Evaluation of the Effects of Ground Shaking and Static Volumetric Strain Change on Earthquake-Related Groundwater Level Changes in Taiwan. Earth, Planets and Space, 62, 391-400.

https://doi.org/10.5047/eps.2009.12.008 